\title{
Sağ Hepatektomi Planlanan Canlı Karaciğer Donör Adaylarında Sol Lob Volümünün Huang Safra Yolu Varyasyonları ile İlişkisi
}

\author{
The Relationship of Left Lobe Volume with Huang Biliary Tract \\ Variations in Living Liver Donor Candidates Planned for Right \\ Hepatectomy
}

Bahar Yılmaz ÇANKAYA, Mutlu AY

Atatürk Üniversitesi Tip Fakültesi, Radyoloji Anabilim Dalı, Atatürk Üniversitesi, Erzurum, Türkiye

Correspondence Address

\section{Bahar Yılmaz ÇANKAYA}

Atatürk Üniversitesi Tip Fakültesi,

Radyoloji Anabilim Dalı, Erzurum, Türkiye

E-posta:dr.bycankaya@gmail.com
Yazışma Adresi

\section{ÖZ}

Amaç: Huang sınıflandırmasına göre, safra kanalı varyasyonlarının canlı donörlerde karaciğer kalıntı hacmi üzerine etkisini araştırmak.

Gereç ve Yöntemler: Yüz altmış dokuz canlı donöre ait, trifazik batın Bilgisayarlı Tomografi (BT) ve manyetik rezonans kolanjiopankreatografi (MRKP) görüntüleri retrospektif olarak incelendi. MRKP ile safra yolları huang sınıflamasına göre dört kategoriye ayrıldı. BT görüntülerinden özel bir bilgisayar programiyla (Myrian Pro; Intrasense, Montpellier, France) karaciğer total ve lobar volümleri hesaplandı. Sol lob volümü total volume oranlanarak sol lob volüm yüzdesi bulundu. Huang smnflaması kategorisel verileri ile sol lob volüm yüzdesi verileri Kruskal-Wallis testi aracilığıyla karşılaştırıldı. İstatistiksel olarak $\mathrm{P}<0.05$ olan değerler anlamlı kabul edildi.

Bulgular: Huang sınıflamasına göre kategoriler arasında yaş ve cinsiyet dağılımında istatistiksel fark izlenmedi (sırasıla; $p=0,756$ ve $p=0,124)$. Karaciğer transplantasyon rezeksiyon hattına (Cantlie hattı) göre hesaplanan remnant sol lob volümleri ile Huang sinıflamasındaki gruplar arasında anlamlı ilişki saptanmadı $(\mathrm{p}=0,354)$.

Sonuç: Sağ hepatoktomi planlanan canlı karaciğer vericilerinde safra yollarındaki varyasyonların remnant sol lob volümünü etkilemediği sonucuna varıldı.

Anahtar Sözcülkler: Bilgisayarlı tomografi, Karaciğer kalıntı hacmi, Manyetik rezonans kolanjiopankreatografi, Safra yolu varyasyonları

Bu makaleve yapılacak atuf:

Cite this article as:

Çankaya BY, Ay M. Sağ hepatektomi planlanan canlı karaciğer donör adaylarında sol lob volümünün huang safra yolu varyasyonları ile ilişkisi. Akd Tip D 2021; 7(2):296-300

Bahar Yılmaz ÇANKAYA ORCID ID: 0000-0001-5395-3276 Mutlu AY

ORCID ID: 0000-0002-3102-3841

\begin{abstract}
Objective: To investigate the effect of bile duct variations on liver remnant volume in living donors, according to the Huang classification.

Material and Methods: Triphasic abdominal Computed Tomography (CT) and magnetic resonance cholangiopancreatography (MRCP) images of one hundred sixty-nine live donors were analyzed retrospectively. Biliary tracts were divided into four categories according to the Huang classification. Liver total and lobar volumes were calculated from CT images with a special computer program (Myrian Pro; Intrasense, Montpellier, France). The volume was proportional to the left lobe volume percentage. The categorical data of the Huang classification and the percentage of left lobe volume were compared using the Kruskal-Wallis test. Values with $\mathrm{P}<0.05$ were considered statistically significant.

Results: According to Huang classification, there was no statistical difference in age and gender distribution between categories $(\mathrm{P}=0.756$ and $\mathrm{P}=0.124$, respectively). There was no significant relation between the groups in Huang classification and remnant left lobe volumes calculated through the liver transplantation resection line (Cantlie line) $(\mathrm{P}=0.354)$.

Conclusion: It was concluded that variations in biliary tract did not affect the remnant left lobe volume in living liver donor candidates planned for right hepatectomy.
\end{abstract}

Keywords: Biliary tract variations, Computed tomography, Magnetic resonance cholangiopancreatography, Remnant volume 


\section{GİRIŞ}

Karaciğer nakli, terminal dönem karaciğer hastalığı olan birçok hastayı hayata bağlarken binlercesi için de umut olmaya devam ediyor. Günümüzde canlı vericilerden yapılan nakil sayısı giderek artmaktadır. Kadavra nakillerinden farklı olarak, canlı vericili transplantasyonda, alıcıya yeterli karaciğer dokusu sağlamak kadar verici için güvenli sınırlarda kalan karaciğer hacminin belirlenmesi de önemlidir. Karaciğer hacmi, kişinin vücut kitle indeksine, anatomik yapısına, ırkına, ve cinsine bağlı olarak değişebilir $(1,2)$. Ayrıca, karaciğerdeki vasküler varyasyonların total ve lobar karaciğer hacimlerini değiştirebileğini gösteren çalışmalar mevcuttur (3). Canlı karaciğer vericilerinde preoperatif cerrahi planlama için safra yollarındaki varyasyonları konu alan çalışmalar $(4,5)$ olsa da bu varyasyonların karaciğer volümlerini etkileyip etkilemediği ile ilgili çalışma yoktur. Biz bu konu üzerine yoğunlaştık ve canlı karaciğer verici adaylarında Huang sinıflamasına göre safra yolu varyasyonlarının karaciğer volümleri üzerine etkisi olup olmadığını araştırdık.

\section{MATERYAL VE METOD}

\section{Hasta seçimi}

Çalışma, 1964 Helsinki Bildirisi'nde belirtilen etik standartlarına göre yapıldı. Erzurum Atatürk Üniversitesi Klinik Araştırmalar Etik Kurulu 26/06/2020 tarih ve B.30.2.ATA.0.01.00/329 sayılı kararı ile çalışma için etik kurul onayı alınmıştır. Çalışmamızda araştırma ve yayın etiğine uyulmuştur. Tüm vericiler muayene ve prosedür hakkında bilgilendirilmiş ve yazılı onamları alınmıştır.

Hastanemiz radyoloji departmanına Temmuz 2018 - Ocak 2020 tarihleri arasında transplantasyon vericisi olmak için başvuran yaş ortalaması 18-55 yıl olan 180 sağlıklı gönüllünün radyolojik ve laboratuvar verileri retrospektif olarak gözden geçirildi. Karaciğer yağlanması olan sekiz olgu, BT ve MRKP görüntüleri volüm ölçüm ve safra yollarını değerlendirmeye uygun olmayan üç olgu çalışma dışı bırakıldı. Geriye kalan 169 gönüllünün verileri çalışmada değerlendirildi.

\section{Manyetik Rezonans \\ Kolanjiopankreatikografi (MRKP)}

Bu çalışmada, MRKP, 3 Tesla (Siemens Skyra,Erlangen, Almanya) MR sistemi ile solunum tetiklemeli, aksiyel ve koronal düzlemlerde HASTE sekansı (TR:1600msn TE:95msn, kesit kalınlığı:5mm FOV:37x29cm) ve koronal düzlemde T2 SPACE sekansı (TR:4500, TE:700, kesit kalınlığı: $1 \mathrm{~mm}, \mathrm{FOV}: 37 \times 37 \mathrm{~cm}$ ) kullanılmıştır.

\section{Bilgisayarlı Tomografi (BT)}

Trifazik batın BT görüntüleri için 320 sıralı çok dedektörlü bir BT cihazı (Aquillion ONE Vision; Toshiba Medical
Systems Corporation, Otawara, Japonya) kullanılmıştır. BT parametrelerimiz; dilim kalınlığı, 0,5 mm; dönme süresi, 0,5 saniye; ve tarama aralı̆̆ı, $240 \mathrm{~mm}$ [480 dilim 0,5 mm] idi. Tüm olgularda otomatik enjektör ile $3,5 \mathrm{ml} / \mathrm{sn}$ hızla 1,5 $\mathrm{mL} / \mathrm{kg}$ oranında BT kontrastı (300 mg / mL iyodeksol) uygulandı. Arteryel, portal ve hepatik ven fazlarmda olacak şekilde trifazik görüntüler elde edildi. Görüntüler radyolojik iş istasyonuna (Syngo Via Console, yazılım sürümü 2,1, Siemens AG Medical Solutions, Erlangen, Almanya) aktarıldı. Karaciğerin volumetrik hacim ölçümleri 10 yıllık deneyime sahip tek radyolog tarafindan özel bir yazılım programı (Myrian Pro; Intrasense, Montpellier, Fransa) aracılığıyla yapıldı.

\section{Görüntü değerlendirme}

MRKP görüntülerinden safra yolları Huang sınıflamasına göre değerlendirildi (Şekil 1) ve olgular dört gruba ayrıldı. BT görüntülerinden, transplantasyon sirasında kullanılan Cantlie hatt boyunca (Şekil 2), karaciğer sağ ve sol lob olarak ikiye ayrıldı. Özel yazılım programı ile karaciğer sınırları yarı otomatik olarak çizildi. Çizimler karaciğer dokusu dışına ya da loblar arası cerrahi hat dışına taşması halinde elle düzeltildi. Karaciğer total ve lobar volumleri ölçüldü. Karaciğer rezeksiyonu sonrası remnant volüm oranı, sol lob volümünün total karaciğer volümüne oranı olarak belirlendi.

\section{İstatistik değerlendirme}

İstatistiksel değerlendirme istatistik program (Medcalc ver. 12, Mariagerke, Belçika) aracılığıyla yapıldı. Verilerin parametrik olup olmadığını belirlemek için D'Agostino-Pearson testi kullanıldı. Huang safra yolu sinıflamasına göre oluşan dört grubun karaciğer sol lob yüzdeleri Kruskal-Wallis test aracılığıyla karşılaştırıldı. Gruplar arasındaki demografik veriler yaş için T-testi ve cinsiyet için Ki-kare testi ile karş1laştırmalı olarak değerlendirildi. İstatistiksel olarak $\mathrm{p}<0.05$ olan değerler anlamlı kabul edildi.

\section{BULGULAR}

Değerlendirmeye alınan 169 canlı donörün ortalama yaşı $28 \pm 8.5$ yıldı. Kadın sayısı 70 (\%41) idi. Huang sinıflamasina göre dört gruba ayrılan olgularda en s1k tip 1; \%71 $(\mathrm{n}=121)$ ve en az tip 4; $\% 3(\mathrm{n}=5)$ varyasyona rastland. Gruplar arasında yaş ve cinsiyet dağılımda istatistiksel fark izlenmedi (sırasıyla; $p=0,756$ ve $p=0,124)$. Karaciğer sol lob volum verileri non-parametrik olup normal dağılım göstermemekteydi. Huang safra yolu gruplarında (Tip 1, 2, 3 ve 4) karaciğer sol lob volum yüzdeleri ortanca değeri (\%95 güven aralığıyla) sirasıyla $\% 36, \% 35, \% 37, \% 40$ bulunmuştur (Şekil 3). Karaciğer rezeksiyon hattına göre, sol lob remnant yüzdesi Huang sinıflamasındaki gruplar arasında değişkenlik gösterse de istatistiksel olarak anlamlı fark izlenmedi $(p=0.354)$. Olgulara ait temel bilgiler, 
Tablo I: Huang sınıflamasına göre olgulara ait temel bilgiler, sol lob volüm yüzdeleri ve istatistiksel sonuçlar.

\begin{tabular}{lccccc}
\hline & huang tip 1 & huang tip 2 & huang tip 3 & huang tip 4 & p \\
\hline Vaka sayısı(n) & $121 \% 72)$ & $20(\% 12)$ & $23(\% 14)$ & $5(\% 3)$ & \\
\hline Yaş & $30,8+-8.5$ & $29,7+-8,7$ & $28,7+-8,7$ & $27,8+-7,5$ & 0,756 \\
\hline Cinsiyet, Erkek (\%) & $71(\% 58)$ & $9(\% 45)$ & $16(\% 69)$ & $3(\% 60)$ & 0,124 \\
\hline Sol volüm yüzdesi (\%95CI güven aralığı) & $36(35-37)$ & $35(32,5-37,5)$ & $37(34-38)$ & $40(37-42)$ & 0,354 \\
\hline
\end{tabular}

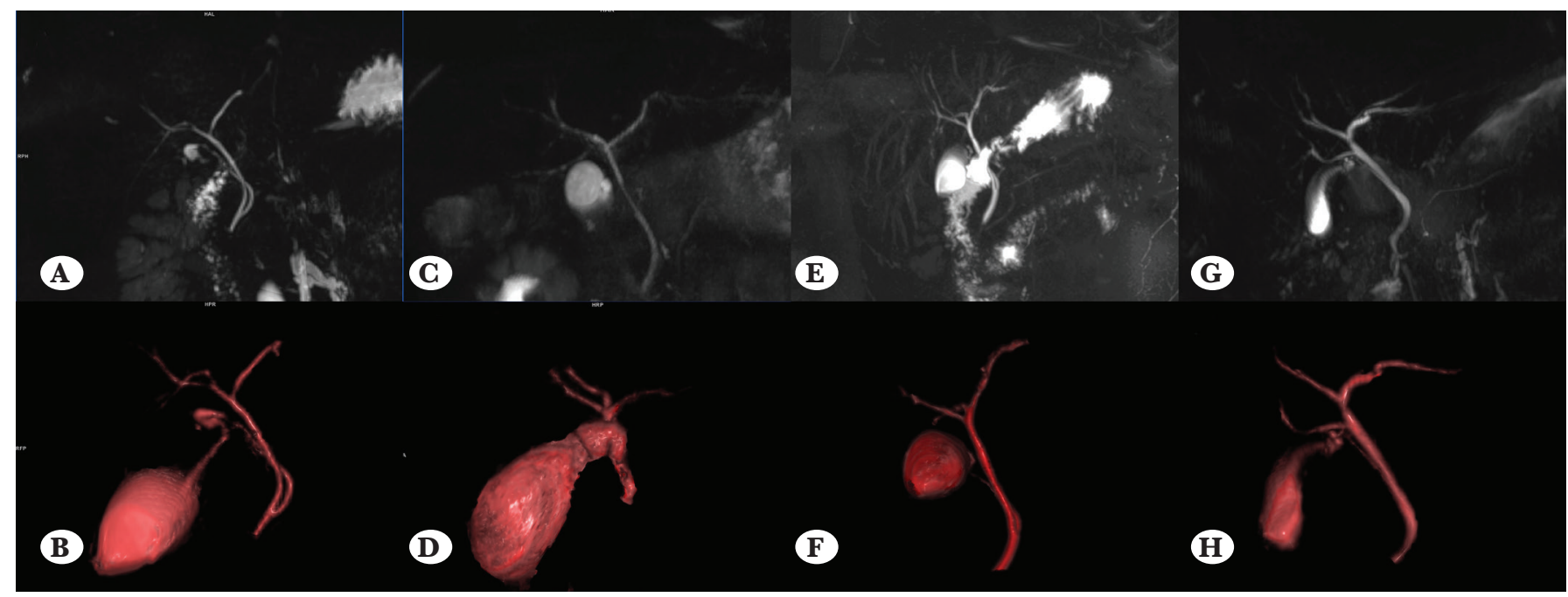

Şekil 1: A-H: MRKP ile safra yolları varyasyonlarının Huang sınıflamasına göre dört tipe ait Maksimum yoğunluk projeksiyonu (MIP) ve 3 Boyutlu görüntüleri. MIP görüntülerde sirasiyla Huang tip 1,2,3,4; A, C, E, G ve 3 Boyutlu görüntüleri sirasılyla; B, D, F, H.

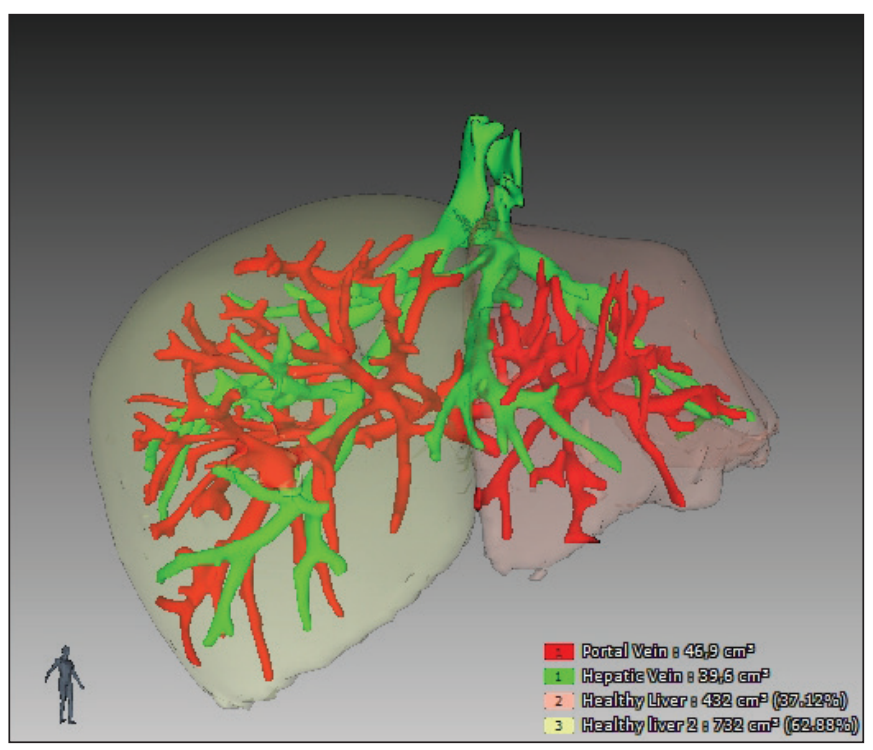

Şekil 2: BT görüntülerinden, transplantasyon sirasında kullanılan Cantlie hattı boyunca, karaciğer sağ ve sol lob olarak ikiye ayırıp total, lobar hacimlerin hesaplanması ve sol lob kalıntı (remnant) karaciğer hacim yüzdesinin bulunması.

Huang sinıflamasına göre volüm değerleri ve istatistiksel sonuçlar Tablo I'de gösterilmiştir.

\section{TARTIŞMA}

Karaciğer transplantasyonunda uygun donörün belir-

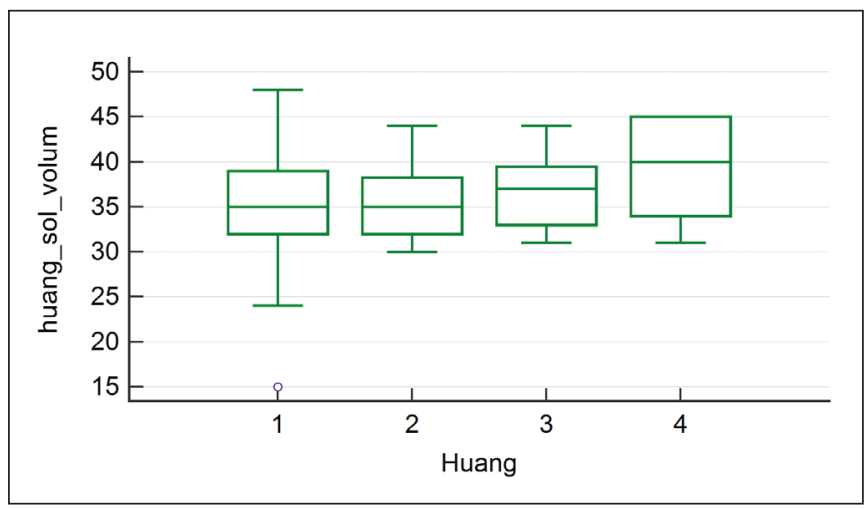

Şekil 3: Huang sinıflamasına göre gruplardaki karaciğer sol lob hacim yüzdelerinin istatistiksel grafiği.

lenmesinde ve komplikasyonların önlenmesinde hacim ölçümlerinin doğru yapılması önemlidir. Karaciğger total ve lobar hacimleri, organın kompleks yapısı nedeni ile birçok faktörden etkilenmektedir. Bugüne kadar ırk, cinsiyet, kişinin fiziksel özellikleri ve vasküler varyasyonlar ile hacim arasındaki ilişkiyi inceleyen çalışmalar yapılmıştır. Safra yollarındaki varyasyonları konu alan yayınlar ise daha çok cerrahi planlama ve cerrahi komplikasyonların önlenmesine yönelik tanımlamalardan ibarettir. Biz, literatürdeki çalışmalardan farklı olarak safra yollarındaki varyasyonların canlı sağ lob karaciğer verici adaylarında sol lob volümüne etkisini araştırdık. 
Karaciğer anatomisi morfolojik ve fonksiyonel olmak üzere iki açıdan incelenebilir. Falsiform ligaman ile ayrılmış sağ ve sol loblar morfolojik bir sınıflamanın ürünü olup lob kelimesi tam anlamılla fissür veya oluklar ile sinırlandırılmış karaciğer parankimini tanımlar (6). Loblar arasındaki boyut farkı embriyolojik dönemdeki intrahepatik olarak dağılım gösteren portal venöz yapıların dallanması ile korelasyon göstermektedir (7). Fonksiyonel anatomi ise portal dallarm ve hepatik venlerin lokalizasyonuna göre tanımlanmış olup hepatik segmentasyona olanak sağlar (8). Cerrahi olarak rezeksiyona önderlik eden bu sinıflamanın portal venöz dağılıma tam uymaması yeni modeller geliştirilmesine yol açmış ve karaciğerin perfüzyonuna ve metabolik ihtiyacına göre adapte olan segmental bir anatomik modelleme gündeme gelmiştir (8). Couinaud'un çalışması kadar eski olan diğer bir çalışmada ise Healey bu segmentasyonu hepatik arter ve safra yollarına göre tarif etmiştir (9). Hepatik arter ve safra yolları dağılıma göre yapılan segmentasyonun birçok haklı sebebi bulunmaktadır. Sol portal ven fetal hayatta kanın plasentadan kalbe yönlendirilmesinde özel bir rol oynamaktadır (10). Bu nedenle sol portal venin tamamı dalları ile birlikte sol lobun yüzeyinde yer almaktadır. Bu durum bifid bir patternde dallanma gösteren ve intrahepatik seyirli sağ portal venden oldukça farklıdır. Sağ portal venin seyri arter ve safra yolları ile uyum içerisindedir. Buna karşın sol portal ven fetal hayattaki ihtiyaçtan dolayı irregüler bir dallanma gösterdiği için sol lob segmentasyonunda safra yolları ve arteryel yapıları rehber edinmek daha mantıklı görünmektedir (10).

Safra yolları, alışlagelmiş normal anatomik görünümü dışında intrahepatik ya da ekstrahepatik bölümlerinde gelişimsel varyasyonlar gösterebilmektedir $(11,12)$. Literatürde safra yolu varyasyonlarının değerlendirilmesinde sıklıkla kullanılan sinıflama Huang sinıflamasıdır (13). Bu sinıflamada varyasyonlar sağ posterior hepatik kanalın drenajına göre 5 alt tipe ayrılmıştır (Tablo II). Farklı popülasyonlarda varyasyon tiplerinin sıklığı değişmektedir. Dünya genelinde Huang tip 1 varyasyon yaygindır. Almanya'da ise en sik tip 5 varyasyon izlenmektedir (14). Ülkemizinde yapılan, 112 canlı karaciğer verici adayının değerlendirildiği bir çalışmada en sık tip 1 varyasyonun tespit edildiği $(\% 55)$ bildirilmiş olup tip 5 dallanmaya hiç rastlanmamıştır (15). Benzer şekilde olgularımızda safra yollarının en sık Huang tip 1 varyasyonel dallanma (\%72) gösterdiğini tespit ettik. Bizim de Huang tip 5 safra yolu dallanması gösteren olgumuz yoktu.

Çalışmamızda, gruplar içerisinde sol lob volüm yüzdesi değeri en yüksek olan tip 4 varyasyon gösterenler (\%40) iken, tip 2 varyasyon gösterenler $\% 35$ median değeri ile en düşük volüm yüzdesine sahipti. Huang sinıflamasına göre 4 gruba ayırdığımız canlı donör adaylarımızın hepsinde sol lob volüm yüzdesi, güvenli sınır olarak kabul gören \%30 değerinin üzerinde bulundu. Literatürde bu konuda yapılmış çalışma olmadığı için verilerimizi karşılaştırma imkanımız olmadı.

Literatürde mevcut birçok çalışmada cinsiyetler arasında anatomik varyasyon açısından istatistiksel olarak anlamlı bir fark olmadığı belirtilmektedir $(16,17)$. Çalışmamızda Ki-kare testi ile yapılan değerlendirmede safra yolu varyasyonları ile cinsiyet arasında anlamlı bir ilişki saptanmadı $(p=0,124)$. Ayrıca safra yolu varyasyonları ile yaş arasında da anlamlı bir ilişki yoktu $(\mathrm{p}=0,756)$.

Çalışmamızın en önemli kısıtllılı̆̆ belli bir coğrafik bölge içerisindeki olguları kapsamasından dolayı sonuçlarımızın ülke genelini temsil etmemesi ve ölçümlerin tek bir radyolog tarafindan yapılmış olmasıdır.

\section{SONUÇ}

Sonuç olarak, Huang sinıflamasına göre safra yolu varyasyonları baz alınarak oluşturulan dört ayrı çalışma grubu arasında karaciğer sol lob volüm yüzdesi sayısal değişkenlik gösterse de istatistiksel olarak anlamlı fark izlenmedi ve karaciğer sol lob volüm ve volüm yüzdesinin, safra yollarındaki varyasyonlardan etkilenmediği sonucuna varıldı.

Finansman veya Mali Destek: Yoktur

Çıkar Çatışması: Yoktur

Etik Kurul: Erzurum Atatürk Üniversitesi Klinik Araştırmalar Etik Kurulu 26/06/2020 tarih ve B.30.2.ATA.0.01.00/329 sayılı kararı ile çalışma için etik kurul onayı alınmıştır.

\section{Yazarların Katkısı:}

Çalışmanın konsepti ve dizaynı: BYÇ, MA

Verilerin toplanması ve işlenmesi: BYÇ, MA

Tablo II: Huang’a göre safra kanalı varyasyonları.

\begin{tabular}{lll}
\hline Tip I & Bifurkasyon & $\begin{array}{l}\text { Sağ posterior ve anterior hepatik kanal karaciğer hilusunda birleşir săg hepatik kanalı } \\
\text { oluşturur o da sol hepatik kanal ile birleşir }\end{array}$ \\
\hline Tip II & Trifurkasyon & Sağ anterior ve posterior hepatik kanal sol hepatik kanal ile ayrı ayrı birleşir \\
\hline Tip III & Aberan drenaj & Sağ posterior hepatik kanal sol hepatik kanala aberan drene olur \\
\hline Tip IV & Aberan drenaj & Sağ posterior hepatik kanal ana hepatik kanala aberan drene olur \\
\hline Tip V & Aberan drenaj & Sağ posterior hepatik kanal sistik kanala aberan drene olur \\
\hline
\end{tabular}


Verilerin analizi ve yorumlanmass: BYÇ, MA

Literatür araştırması: BYÇ

Makalenin yazımı: BYÇ, MA

\section{KAYNAKLAR}

1. Andersen V, Sonne J, Sletting S, Prip A. The volume of the liver in patients correlates to body weight and alcohol consumption. Alcohol and Alcoholism 2000; 35 (5): 531-32.

2. Kokudo T, Hasegawa K, Uldry E, Matsuyama Y, Kaneko J, Akamatsu N, Taku Aoki T, Sakamoto Y, Demartines N, Sugawara Y, Kokudo N, Halkiç N. New formula for calculating standard liver volume for living donor liver transplantation without using body weight. J Hepatol 2015; 63(4): 848-54.

3. Choi SH, Kwon JH, Kim KW, Jang HY, Kim JH, Kwon HJ, Lee J, Şarkısı JL,Won G, Lee SG. Measurement of liver volumes by portal vein flow by Doppler ultrasound in living donor liver transplantation. Clin Transplant 2017; 31: e13050.

4. Abdalla EK, Denys A, Chevalier P, Nemr RA, VautheyJN. Total and segmental liver volume variations: implications for liver surgery. Surgery 2004;135(4):404-10.

5. Basaran C, Agildere AM, Donmez FY, Sevmis S, Budakoglu I, Karakayali H, Haberal M. MR cholangiopancreatography with T2-weighted prospective acquisition correction turbo spin-echo sequence of the biliary anatomy of potential living liver transplant donors. AJR Am J Roentgenol 2008;190(6):1527-33.

6. Bismuth H. Surgical anatomy and anatomical surgery of the liver. World J Surg. 1982;6 (1):3-9.

7. Hikspoors JPJM, Peeters MMJP, Kruepunga N, Mekonen HK, Mommen GMC, Köhler SE et al. Human liver segments: role of cryptic liver lobes and vascular physiology in the development of liver veins and left-right asymmetry. Sci Rep. 2017;7(1):17109.

8. Couinaud, C. (Masson, Paris, 1957).

9. HEALEY JE Jr, SCHROY PC. Anatomy of the biliary ducts within the human liver; analysis of the prevailing
Kritik gözden geçirme: BYÇ, MA

Yayınlanacak versiyonun nihai onayı: BYÇ, MA pattern of branchings and the major variations of the biliary ducts. AMA Arch Surg. 1953;66(5): 599-616.

10. Strasberg SM. Nomenclature of hepatic anatomy and resections: a review of the Brisbane 2000 system. J Hepatobiliary Pancreat Surg. 2005;12(5): 351-55.

11. Dohke M, Watanabe Y, Okumura A, Amoh Y, Oda K, Ishimori T, Koike S, Hayashi T, Hiyama A, Dodo Y. Anomalies and anatomic variants of the biliary tree revealed by MR cholangiopancreatography. AJR Am J Roentgenol 1999; 173:1251-54.

12. Düşünceli E, Erden A, Erden I. Biliyer sistemin anatomik varyasyonları: MRKP bulguları. Tanısal ve Girişimsel Radyoloji 2004;10:296-303.

13. Huang TL, Cheng YF, Chen CL, Chen TY, Lee TY. Variants of the bile ducts: clinical application in the potential donor of living-related hepatic transplantation. Transplant Proc 1996; 28:1669-70.

14. Wietzke-Braun P, Braun F, Müller D, Lorf T, Ringe B, Ramadori G. Adult-to-adult right lobe living donor liver transplantation: Comparison of endoscopic retrograde cholangiography with standard T2-weighted magnetic resonance cholangiography for evaluation of donor biliary anatomy. World J Gastroenterol 2006; 12:5820-25.

15. Karakas HM, Celik T, Alicioglu B. Bile duct anatomy of the Anatolian Caucasian population: Huang classification revisited. Surg Radiol Anat 2008; 30:539-45

16. Taghavi SA, Niknam R, Alavi SE, Ejtehadi F, Sivandzadeh GR, Eshraghian A. Anatomical Variations of the Biliary Tree Found with Endoscopic Retrograde Cholagiopancreatograhy in a Referral Center in Southern Iran. Middle East J Dig Dis 2017; 9:201-5.

17. Deka P, Islam M, Jindal D, Kumar N, Arora A, Negi SS. An analysis of biliary anatomy according to different classification systems. Indian J Gastroenterol 2014; 33: 23- 30 . 